Journal of Animal and Veterinary Advances 11 (8): 1149-1157, 2012

ISSN: $1680-5593$

(C) Medwell Journals, 2012

\title{
Remarks on the Mating Behavior and Success of Blue Swimming Crab, Portunus pelagicus (Linnaeus, 1766) Through the Induction of Limb Autotomy Technique
}

\author{
${ }^{1}$ W.N. Nadiah, ${ }^{1}$ M. Ikhwanuddin and ${ }^{2}$ A.B. Abol-Munafi \\ ${ }^{1}$ Institute of Tropical Aquaculture, ${ }^{2}$ Department of Fisheries and Aquaculture, \\ University Malaysia Terengganu, 21030 Kuala Terengganu, Malaysia
}

\begin{abstract}
This study investigates the mating behavior and success of commercially important crab, Portunus pelagicus through the induction of limb autotomy technique. In the first treatment, the newly mature female crabs were limb autotomized and only perpetuate the swimming paddles. Second treatment (control) consists of newly mature female crabs (intact crabs) which are placed in a mating tank together with an inter-molt male crab. The female crabs which showed signs of molting were transferred to the mating tank with the ratio of $1: 1$ (male:female). About 2 weeks after the limb autotomy induction, all female crabs in the first treatment has successfully molted and entered the post-molt (soft-shell) stage. The post-molt female crabs were then transferred to mating tanks together with inter-molt male crabs to observe for any mating success. Results for both treatments demonstrate that successful mating among crabs was observed in the first treatment and as for controls no mating process was observed.
\end{abstract}

Key words: Portunus pelagicus, swimming paddles, crabs, soft-shell, mating success, Malaysia

\section{INTRODUCTION}

Blue swimming crabs, Portunus pelagicus are one of the commercially important decapods occupying the coastal water of Indo-West Pacific region (Kailola et al., 1993). Commercial seed production of this species are consider none in Malaysia and most fisherman obtained their seed supply from wild. The dependency on wild crab seeds is not reliable since it acquires a quality, productive and often in high densities and these are known to be the main constraint for a successful culture of this species. Moreover, the effectiveness of stock enhancement of $P$. pelagicus is not verified since there is no reliable method to distinguish hatchery reared crabs from those produced in nature. The impracticality of depending on wild crab seeds may lead to serious questions about the long-term sustainability of the industry. Thus, there should be a drastic measure for establishing a commercial seed production technology in this region. In producing a good hatchery based culture for this species, a quality broodstock is needed. Since, demands for this species is increasing day by day, it is hence important to develop a hatchery technology so that this species could be successfully culture and hence decreases the problems faced by local farmers prior to their failure in most of the small scale seed production trials.

In order for continuous year-round stock production, the availability of large numbers of berried females throughout the year is essential. This is not possible from natural reserves. Therefore, high production of berried females in captivity is seen as the best way to address the need. Prerequisite to this, effective mating process for $P$. pelagicus is a must. To start year round seed production the availability of berried females throughout the year is essential. It is not possible from the natural resources. Hence, the production of berried females in captivity is need of the hour and it is prerequisite to fasten the mating process for $P$. pelagicus under captivity to increase the productivity of berried female crabs. This proposed study was expected to produce effective techniques to shorten the time of producing berried female crabs and to ensure the sustainability of $P$. pelagicus year round seed production.

Decapods crustaceans readily autotomize their walking legs and claws in response to injury or predation; lost appendages are regenerated before the next molt (Skinner, 1985; Hopkins, 1993). Thus, limb regeneration

Corresponding Author: W.N. Nadiah, Institute of Tropical Aquaculture, University Malaysia Terengganu, 21030 Kuala Terengganu, Terengganu, Malaysia 
and molting are obligatorily linked. Limb regeneration is divided into two distinct phases; basal growth or regeneration which can occur at any time during the inter-molt cycle and involves primarily cell division and differentiation and results in the formation of basal papillae and proecdysial growth which is restricted to the proecdysial period (mostly $D_{0}$ ) involves primarily protein synthesis and water uptake and is under hormonal control (Hopkins, 1993). During molting, crustaceans become soft and inflated with water. This process is consistent with that of an animal possessing a hydrostatic skeleton. Among crustaceans, it has been hypothesized that the soft water-inflated body of the newly molted blue crab, Callinectes sapidus may rely on a hydrostatic skeleton that is comparable to that known from annelids and cnidarians (Taylor and Kier, 2003). Seidel (2005) has done a study on the rapid hydrostatic limb inflation in the prawn Macrobranchium Lar. Comparison of the calculated means in his studies shows that prawns with two autotomized chelipeds were able to regenerate and elongate lost organs faster than prawns missing only one cheliped. Previous studies also reported that increasing the number of autotomized limbs decreased the length of the molt cycle in the fiddler crab Uca pugilator (Hopkins, 1993).

Since, $P$. pelagicus mate immediately after the female's final molt hence, it is important to find ways in accelerating the molting cycle of the female crabs in order to proceed with the mating process. Female crabs are physically able to mate only when their exoskeleton is soft, immediately after molting. Through this study, observations were made on the mating behavior and success in $P$. pelagicus using the limb autotomy technique as a tool in accelerating molting for mating events to occur and to help in shortening the time for production of berried female crabs in $P$. pelagicus aquaculture industry.

\section{MATERIALS AND METHODS}

Sampling and study site: The experimental male and female crabs were obtained from East Coast of Peninsular Malaysia of South China sea. Newly mature female crabs with size ranging from $9.5-12.0 \mathrm{~cm}$ were selected and brought back to Institute of Tropical Aquaculture, University Malaysia Terengganu, Terengganu, Malaysia. Crab size is measured as the external carapace width which is the distance between the tips of 9th antero-lateral spines of the carapace. All the crab samples were acclimatized to the hatchery condition (Fig. 1).

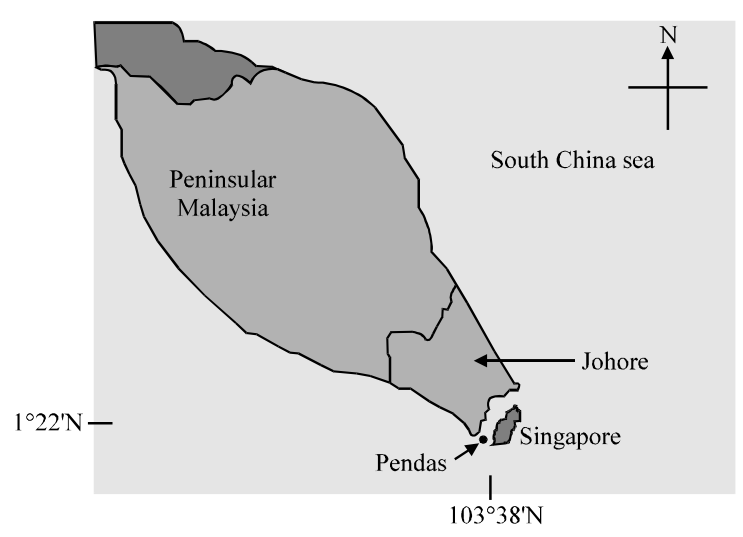

Fig. 1: Sampling site at Pendas of Strait of Johor, Johor

Crab selection for limb autotomy technique: Limb autotomy technique was applied to crabs with gonad development stage three. Female crabs with Carapace Width (CW) range of 9.5-11.9 cm and Body Weight (BW) of 105-130 g were selected for limb autotomy process.

Limb autotomy technique: Limb autotomy technique was done to the experimental crabs by cutting off the pincers and walking legs and only perpetuates the swimming paddles. A sharp cutter was used to cut at a joint between the carpus and merus of the pincers. Subsequently, three pairs of legs were casted off by cutting the periopod merus using the cutter. The swimming paddles were not cut to allow the crab to swim. Next, all autotomized crabs were cultured in tanks for observation of molting events.

Experimental design: The experimental designs consist of two treatments. The first treatment comprised of five newly mature female crabs of gonad development stage three and undergone limb autotomy technique on its walking legs. Only swimming paddles were left perpetuate. The female crabs were observed for any sign of molting everyday before it could be transferred to the mating tanks for observation of mating success. After 14 days of experiment, the female crabs have shown sign of molting. The post-molt (Holland and Skinner, 1976) crabs were transferred to the mating tank with the ratio $1: 1$ (male:female) in each tanks. Five tanks were used in the first treatment with one paired crabs in each tanks.

The second treatment acts as control. Five mating tanks were used in this part with each consists of one newly mature female crab and one inter-molt male crab. Optimum environmental parameters were maintained 


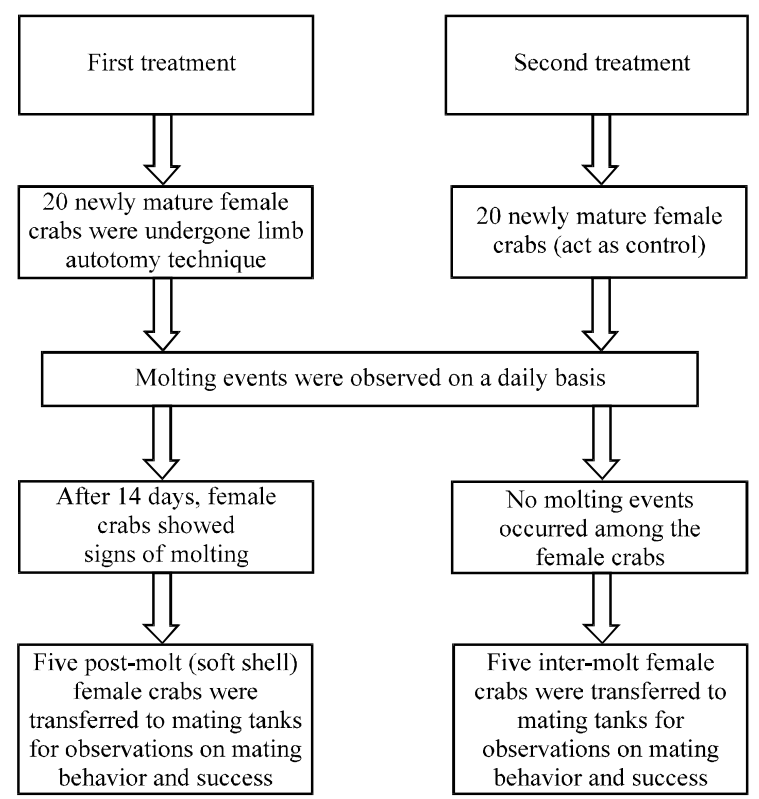

Fig. 2: Schematic diagrams on the experimental design in this study

during the experimental period (salinity $30-32 \mathrm{ppt}$, temperature $26-31^{\circ} \mathrm{C}, \mathrm{pH} \quad 7.5-8.2$ and dissolved oxygen 5 ppm) (Fig. 2).

Statistical analysis: Statistical analyses were performed by SPSS Software (Version 11.5) to test the mean significance levels between intact and limb autotomized crabs using independent samples t-test. Molting durations for limb autotomized and intact crabs were taken. Observations on the mating behavior and success were daily recorded and images were captured for both treatments; mating pairs through limb autotomy process and mating pairs from control treatment.

\section{RESULTS AND DISCUSSION}

Molting duration in $P$. pelagicus in intact and induced with limb autotomy crabs: Results have showed that limb autotomy technique is the best stimulant to induce molting in $P$. pelagicus. Most of the female crabs molt after $14.65 \pm 0.93$ days induced with limb autotomy (Table 1). In intact female crabs of $P$. pelagicus, molting was only displayed after $49.85 \pm 15.12$ days of experiment (Table 1). The experiment last for 80 days and the longest duration for successful molting to occur were 78 days which is observed in intact female crabs. There is a significant difference between control and limb autotomy technique (ANOVA, $\mathrm{p}<0.05$ ) on the duration of molting represent by each crabs. These results proved that limb
Table 1: Duration of molting in control and limb autotomy treatment for each crab

\begin{tabular}{|c|c|c|c|}
\hline \multicolumn{2}{|l|}{ Control } & \multicolumn{2}{|l|}{ Limb autotomy } \\
\hline Crab number & Duration (days) & Crab number & Duration (days) \\
\hline$* \mathrm{C} 1$ & 33.00 & $\mathrm{C} 1$ & 16.00 \\
\hline $\mathrm{C} 2$ & 56.00 & $\mathrm{C} 2$ & $14.00^{*}$ \\
\hline C3 & 67.00 & C3 & $14.00^{*}$ \\
\hline $\mathrm{C} 4$ & 48.00 & $\mathrm{C} 4$ & $14.00^{*}$ \\
\hline $\mathrm{C} 5$ & 65.00 & $\mathrm{C} 5$ & $14.00^{*}$ \\
\hline C6 & 58.00 & C6 & 17.00 \\
\hline $\mathrm{C} 7$ & 25.00 & $\mathrm{C} 7$ & 15.00 \\
\hline C8 & 45.00 & $\mathrm{C} 8$ & $14.00^{*}$ \\
\hline $\mathrm{Cg}$ & 54.00 & $\mathrm{C} 9$ & 16.00 \\
\hline $\mathrm{C} 10$ & 78.00 & $\mathrm{C} 10$ & 15.00 \\
\hline $\mathrm{C} 11$ & 34.00 & $\mathrm{C} 11$ & 14.00 \\
\hline $\mathrm{C} 12$ & 67.00 & $\mathrm{C} 12$ & 14.00 \\
\hline $\mathrm{C} 13$ & 55.00 & $\mathrm{C} 13$ & 14.00 \\
\hline C14 & 44.00 & $\mathrm{C} 14$ & 14.00 \\
\hline $\mathrm{C} 15$ & 34.00 & $\mathrm{C} 15$ & 16.00 \\
\hline C16 & 67.00 & $\mathrm{C} 16$ & 14.00 \\
\hline $\mathrm{C} 17$ & 56.00 & $\mathrm{C} 17$ & 15.00 \\
\hline $\mathrm{C} 18$ & 43.00 & $\mathrm{C} 18$ & 15.00 \\
\hline C19 & 23.00 & C19 & 14.00 \\
\hline $\mathrm{C} 20$ & 45.00 & $\mathrm{C} 20$ & 14.00 \\
\hline Mean & 49.85 & Mean & 14.65 \\
\hline Max & 78.00 & $\operatorname{Max}$ & 17.00 \\
\hline Min & 23.00 & Min & 14.00 \\
\hline SD & 15.12 & $\mathrm{SD}$ & 0.93 \\
\hline $\mathrm{N}$ & 20.00 & $\mathrm{~N}$ & 20.00 \\
\hline
\end{tabular}

*C: Number of crabs $(20$ crabs). *Bold: 5 female crabs which have successfully molted were used in pairing up with male crabs to observe for any mating success

Table 2: Mean of mating frequency in control and limb autotomy treatment

\begin{tabular}{lccc}
\hline Treatment groups & $\begin{array}{c}\text { Sample } \\
\text { size (n) }\end{array}$ & $\begin{array}{c}\text { Mating frequency } \\
\text { on five paired crabs }\end{array}$ & Mean \\
\hline *Control & 5 & $0,0,0,0,0$ & 0 \\
* Limb autotomy treatment & 5 & $1,1,1,1,1$ & 1 \\
\hline
\end{tabular}

*Control: Inter molt female+Inter molt male; **Limb autotomy treatment: Post molt female+Inter molt male

autotomy have a significant effect in stimulating precocious molts compared to intact crabs. Limb autotomy technique fastens the production of post molt female crabs and therefore allows successful mating to occur. The successful molting female crabs (post-molt) were then transferred to mating tanks together with intermolt male crabs for mating process to ensue.

Mating frequency and observations on mating behavior in P. pelagicus: About 14 days (14.65 \pm 0.93 days) after induction of limb autotomy, the female crabs in the first treatment begin to exemplify positive signs towards molting. Five female crabs that have successfully entered post-molt stages were then transferred to the mating tanks together with an inter-molt male crab. About second treatments (control) showed no sign of mating among the males and females after 14 days of experiment (Table 2). 


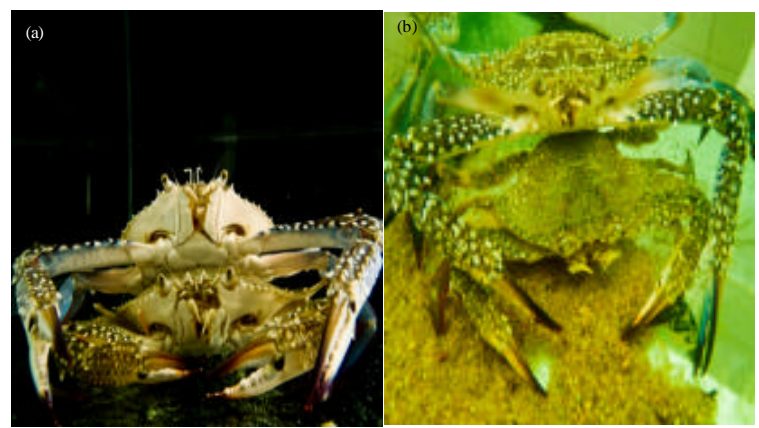

Fig. 3: Crabs in the cradle-carry position (precopulatory embrace); a) Anterior view and b) Dorsal view

Upon introduction of post molt female crabs, the inter molt male crab was triggered and started to perform a courtship ritual and move closer to the post-molt female crabs. In the occurrence of the post-molt female, the intermolt male crabs turned very active, prompt towards the post-molt female and grab her with one of his chelae robustly and turned her over. Both crabs were facing the same direction. This position is known as precopulatory embrace or commonly named as cradle-carry position (Fig. 3).

The male abdomen was exerted and tucked beneath the females so that the copulatory pleopods can be enclosed into the genital apertures of the female. The inter molt male crab deposited its spermatophore into the spermathecae which last for $>8.0 \pm 1.0 \mathrm{~h}$ (Table 3 ). The male gripped the female with his pereiopods so that the female pereiopods are effectively shackled. As a matter of fact until rather late in the copulatory phase, the only evident movement by the female was the mouth parts, particularly the third maxillipeds. Male crabs, on the other hand were capable of relatively performing broad movements. Modest changes in terms of location were showed and male crab made active movements as in forcing the copulatory pleopod of each side alternately into the female aperture. Mostly during copulation the male often walked around with the female attached to its ventral surface, holding her with third and fourth walking legs (Fig. 4). After copulation the cradle- carry position were continued for only few hours $(3.20 \pm 1.10 \mathrm{~h}$ ) (Table 3 ). The female crabs attained the normal hardness of her exoskeleton and were found inactive during this period.

Following copulation, the female is once again clasped and cradle carried, right side up, facing forward, until its shell had fully hardened about $49.20 \pm 1.79 \mathrm{~h}$ (Table 3). The female crabs were then found inactive (remains static) until she attains normal hardness of her exoskeleton. This is known as the post-copulatory embrace (Fig. 5). Results in the limb autotomy treatment

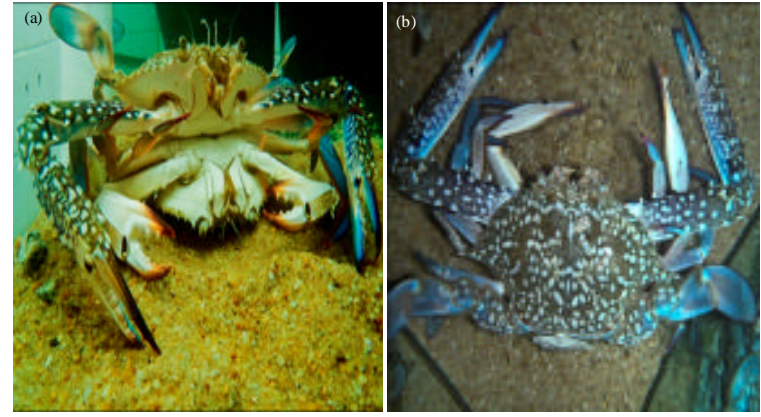

Fig. 4: Crabs under copulation position (copulatory embrace); a) Dorsal view and b) Ventral view

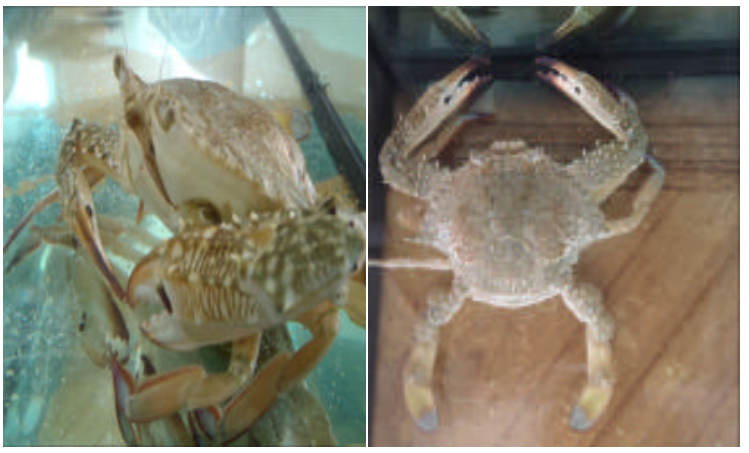

Fig. 5: Female crabs under post-copulation position (post-copulatory embrace)

Table 3: Mean duration (h) taken during each pre-copulatory embrace, copulatory embrace and post-copulatory embrace during the mating process for paired crabs from limb autotomy treatment

\begin{tabular}{|c|c|c|c|}
\hline \multirow[b]{2}{*}{ Crab No. } & \multicolumn{3}{|l|}{ Duration (h) } \\
\hline & $\begin{array}{c}\text { Pre-copulatory } \\
\text { embrace }\end{array}$ & $\begin{array}{c}\text { Copulatory } \\
\text { embrace }\end{array}$ & $\begin{array}{c}\text { Post-copulatory } \\
\text { embrace }\end{array}$ \\
\hline 1 & 7 & 2.00 & 48.00 \\
\hline 2 & 7 & 4.00 & 50.00 \\
\hline 3 & 8 & 4.00 & 48.00 \\
\hline 4 & 9 & 2.00 & 48.00 \\
\hline 5 & 9 & 4.00 & 52.00 \\
\hline Mean & 8 & 3.20 & 49.20 \\
\hline Max. & 9 & 4.00 & 52.00 \\
\hline Min. & 7 & 2.00 & 48.00 \\
\hline $\mathrm{SD}$ & 1 & 1.10 & 1.79 \\
\hline $\mathrm{N}$ & 5 & 5.00 & 5.00 \\
\hline
\end{tabular}

showed that mating was success and observations on the mating behavior appear to be similar for all paired crabs. There were no signs of mating success among the crabs in the control group.

In the present study, molting of females take place 14 days after limb autotomy. Kurup and Adiyodi (1984) had shown the effects of Multiple limb Autotomy (MA) on stimulating precocious ecdysis and ovarian growth on freshwater crab, Paratelphusa hydrodromous. Results from their studies showed that MA induced limb bud formation in $83 \%$ (10 out of 12) young males within 
5-8 days post operation and $58 \%$ completed the process within the mean duration of $31 \pm 2$ days (Kurup and Adiyodi, 1984). In the Brachyurans, it is generally assumed that Multiple Autotomy (MA) inhibits release of Molt-Inhibiting Hormone (MIH) and activates the $\mathrm{Y}$ organ to produce ecdysone which triggers the onset of pre molt and finally ecdysis. Results from the current study using limb autotomy technique on $P$. pelagicus suggest that MA might also be inhibiting release of the GonadInhibiting Hormone (GIH) (Kurup and Adiyodi, 1984). Reaction of the individual to eyestalk ablation as well as to multiple autotomy is dependent on the prevailing phase in physiology at the time of autotomy. Eyestalk ablation eliminates the sources of both $\mathrm{MHH}$ and GIH; Multiple Autotomy (MA) possibly results in restraining the release of both inhibiting factors. In Paratelphusa, the effect of MA varies with age, sex and reproductive status of the individual at the time of autotomy. However, the rate of acceleration of ovarian growth induced by MA is only about half that induced by bilateral eyestalk ablation and is more or less comparable to that induced by unilateral eyestalk ablation (Anilkumar et al., 1981). This however, shows that multiple autotomy is a good stimulant in inducing ecdysis to ensue. Subsequently, others have found multiple autotomy an effective trigger of precocious molts in more than a dozen additional species (Gecarcinus lateralis, Uca pugilator and Uca pugnax) (O'Brien and Skinner, 1990) confirming the results in present study.

The current study has proved that limb autotomy is recognized as the fundamental way to expedite the production of soft-shell female crabs for used in mating process. In numerous brachyuran crabs, the molting cycle is an essential activity during copulation thus the mating males' shells are always hard, so that male gonopods are capable of successfully penetrating the female gonophores. Results from the limb autotomy treatment shows that mating can only take place when hard shelled males and soft shell females were paired. Consequently, all males must have a hard exoskeleton in order for a successful mating. Typically, females are physically able to mate only when their exoskeleton is soft, immediately after molting. Similar mating behavior is also found in Cancridae and Portunidae (Dinakaran and Soundarapandian, 2009) supporting the results in the present study on $P$. pelagicus.

Duration of molting in the present study have indicated that molting successfully occur after $14.65 \pm 0.93$ days being autotomized much faster than other studies that have been conducted before on other crustacean species such as in freshwater crab, Paratelphusa hydrodromous where molting occurs after $31 \pm 2$ days (Kurup and Adiyodi, 1984). Besides, a study on blue crab, Callinectus sapidus have reported that molting occurs after 42 days of autotomy process (Skinner and Graham, 1972). However, similar results was showed in previous study on limb loss of $P$. pelagicus where molting appears after 2 weeks of autotomizing only the walking legs (Paterson et al., 2007).

Autotomy is a reflexive reaction to injury or its threat that results in the casting off of an appendage at a predetermined breakage plane (Rufino and Jones, 2001). Tail autotomy by vertebrates (lepidosaurans, salamanders and rodents) and limb autotomy in asteroids, ophiuroids (Lawrence, 1992) and spiders is usually a reaction to predator attack that facilitates escape but one that also carries ecological costs (Juanes and Smith, 1995). Many decapods crustaceans are capable of autotomizing limbs (as a manifestation of threats) grounds of the response can be found in primitive fossil crabs from the Cretaceous (Rufino and Jones, 2001).

Existing results on limb autotomy technique shows that ecdysis takes place in female crabs before mating is executed. In Crustacean, as in other arthropods molting facilitates extended body growth by periodic shedding of the old cuticle and secretion of a new cuticle. A characteristic feature which is remarkably among other arthropod groups is the continuance of molting even after attaining sexual maturity in many crustacean species. The resultant relationship between molting and reproduction is more marked in females as active vitellogenesis during the reproductive cycle as well as secretion of a new cuticle during molting, could affect the physiology of the organism by their competitive utilization of reserve material from storage organs (Subramoniam, 2000). This confirms the results of current study which indicated that molting in $P$. pelagicus females has a significant relationship with mating process.

In decapods crustaceans, growth and limb regeneration are intimately linked to the molting cycle. Numerous reviews (Maginnis, 2006) have summarized an extensive literature on the physiological effects of limb loss on growth, regeneration and molting frequency. Limb loss can affect crustacean growth and potentially fitness, by reducing size increase at the molt altering the timing of ecdysis and impairing foraging efficiency. Limb loss is known to reduce molt increment (percent increase in carapace width at the molt) in various decapods species (Paterson et al., 2007). Since, chelipeds constitute a substantial portion of the total body weight in many decapods (20\% in Carcinus maenas and Liocarcinus holsatus Lee and Seed (1992) 50\% in Menippe mercenaria, Simonson and Steele (1981), their replacement should divert the largest amount of energy from growth relative to other limb types. It is fairly surprising, then that the loss of one cheliped had no 
effect on size increase at the next molt in Hemigrapsus oregonensis, Cancer pagurus or Callinectes sapidus (Juanes and Smith, 1995). Instar period can either be shortening by autotomy (O'Brien and Skinner, 1990) depending on the timing of the injury with respect to the molt cycle and number and types of limbs lost (Juanes and Smith, 1995). Such variation in molting times may be detrimental if as Reaka (1976) has suggested, molt synchronization is a strategy to avoid cannibalism. Terminal anecdysis occur when regeneration potential and success decreases with size (age) of the individual (Juanes and Smith, 1995). For an example, small blue crabs are capable of regenerating almost $90 \%$ of the normal limb length in the first post-autotomy molt and nearly $100 \%$ of the length regenerated after the second molt (Smith, 1990). Complete regeneration can occur in a single season because small blue crabs molt every 3-4 weeks. Mature female blue crabs in contrast are in terminal anecdysis and can no longer replace missing limbs.

Latest result on mating behavior in $P$. pelagicus suggested that males will copulate with molted females that induced by limb autotomy. In many Crustaceans the male regularly copulates with a female just after she has molted. Examples may be cited from the majority of groups of Crustaceans, notably from branchiopods, copepod, mysidacea, isopoda, amphipods, macrura and brachyuran. The male often attends on or carries the female and may even assist her in freeing herself from the molt before the sexual acts begins. Association of the males with the females before the latter molt is found not only in the higher Crustacean but for example in Portunids (Patei and Crisp, 1961). It is also important for the male to recognize the female when she has molted or is about to molt. In Portunid crabs, sex recognition is tactile (Patei and Crisp, 1961). During oviposition, the soft female is correspondingly passive and does not resist the male (Patei and Crisp, 1961). However, there are many exceptions to this behavior in Crustacean. The habit of consorting with an immature female has an evident advantage to the particular male as against other males. Moreover, the advantage of first finding a virgin female is especially important in species where a single copulation provides the sperms for several broods as is quite common in Brachyurans. The essential feature which may have led to the development of such behavior in the Brachyurans is the fact that the female does not usually mature until immediately after a particular molt. In crabs this molting event reveals the rounded and enlarged abdomen which becomes free to accommodate the egg sponge (Patei and Crisp, 1961).

Copulation and oviposition following ecdysis observed in the present study on $P$. pelagicus and also in other brachyuran may therefore have several advantages. It is probably associated with the development of incubatory accessories. It reduces the risk both of losing stored spermatozoa and of shedding the brood prematurely with the cast skin. The soft condition acquired by the female will also render her a passive partner during copulation (Murata et al., 2006).

The mating system of a population of species depends upon the behavioral strategies utilized by each individual in obtaining mates. In brachyuran crabs, several factors are anticipated to affect the mating system including the timing of mating during the molt stage, the duration of receptivity, the frequency of mating and the pattern of sperm storage (Jennings et al., 2000).

When a male and a molting female of helmet crab (Telmessus cheiragonus) were placed in the same tank, the male grasped and held the female in pre-copulatory guarding position, confirming the same position showed in $P$. pelagicus of the current study. Upon completion of molting the male pulled the female away from its exuviae and held her in the pre copulatory guarding position again. In the present study on $P$. pelagicus when a post molt female crab were introduced to the mating tank together with an inter molt male crab, the inter molt male crab started to perform a courtship ritual and move closer to the post-molt female crabs. In the occurrence of the post-molt female, the inter-molt male crabs turned very active, prompt towards the post-molt female and grab her with one of his chelae robustly and turned her over. Helmet crab also exhibits the same mating behavior which the male held the female in pre copulatory embrace or known as pre-copulatory guarding position shown in the present study on $P$. pelagicus.

In the male blue crab, C. sapidus, courtship is displayed through the elevation of their body by standing high on their legs opening of the chelae and paddling of the swimming legs. This courtship display is not reported in other Portunid crabs (Kamio et al., 2008). Lucas suggested that the conspicuous coloring of some male Hymenosomatids might be evidence of visual displays. Such attractive displays were not observed in $P$. pelagicus of the present study. It is well known however, that blue crabs wave their claws in both agonistic and sexual interactions (Baldwin and Johnsen, 2008). During courtship, males will rise up on the tips of their walking legs extend their claws and sometimes raise their swimming paddles and laterally fan them towards the potential mate (Teytaud, 1971). The higher posture and paddling help send chemical cues towards a potential mate but may serve a visual purpose as well (Kamio et al., 2008). 
Families of Cancridae and Portunidae male's might guard the female until she molts and will proceed with copulation with the female and resume guarding until the females' integument has hardened (Hartnoll, 1969). In the present study, $P$. pelagicus males guarded and protected the female crab until her shell became hardened. Alternatively in some crab species where multiparous females can mate in a hard-shell condition, there is often little pre-copulatory guarding but the male may guard the female for some time following copulation.

Paired crabs of $P$. pelagicus in the present study were always in contact with sandy bottom substrate during the experiment; confirming similar results by Libina emarginata (DeGoursey and Auster, 1992) where paired spider crabs were always in contact with the sandy-mud bottom substrate. DeGoursey and Auster (1992) in his studies reported that male spider crab (Libina emarginata) firmly grasped the female rostrum with his chelae and using his walking legs positioned her abdomen against his in a copulatory posture. His studies also indicated that during copulation the abdominal flaps of both crabs were extended and mating occurred with both crabs standing on their walking legs or with the male lying on his carapace with the female on top of the male. This courtship behavior was also reported in present study on $P$. pelagicus.

Previous study on helmet crab Telmessus cheiragonus (Brachyura: Cheiragonidae) have shown results where pre-copulatory guarding, molting of female, copulation and post-copulatory guarding were observed on its mating behavior; suggesting similar pattern of mating behavior in P. pelagicus of current study. Males carried females before mating without copulatory display were reported in Callinectes sapidus (Teytaud, 1971); upon molting a male pulled of a female from the old carapace which was followed by copulation. After copulation, they carried females again for a short period. Mating behavior in this experiment on $P$. pelagicus have shown a mating styles similar to those perform by $T$. cheiragonus and $E$. Isenbeckii in other studies which involve general features of soft female mating (Hartnoll, 1969); prolonged precopulatory mate guarding, copulation shortly after female molting and postcopulatory guarding. Female crabs which are about to molt release a pheromone that attracts the male (Ryan, 1976) and the male crabs will then protect the female during the vital time by encompassing the female and mates briefly. In this current observation, mating took place in a condition between hard shelled male and newly molted female similar as in many other crabs. Golden crab, Geryon fenneri and in Cyclograpsus lavauxi, Helice crassa, Hemigrapsus crenulatus and $H$. sexdentatus
(Brockerhoff and McLay, 2005) mating was described to occur when the female crabs were in hard-shell (inter-molt) condition. Jaroensatasinee and Jaroensatasinee (2003) studied the courtship in $U$. paradussumieri. In their study, they have observed male courtship displayed in the form of claw waving to attract the females to the burrows of males for mating.

Gleeson (1980) in his studies indicated that the pheromone signal is of primary vital for initiating the male's courtship behavior and those visual cues are secondarily used to point this behavior towards any crab in the immediate locality. In the present investigation it is uncertain whether the male $P$. pelagicus was attracted by pheromone or visual cues. Teytaud (1971) verified that pubertal C. sapidus female exhibited significant changes in particular behaviors like rocking and chelae waving when presented with a visual image of a crab and concurrently exhibited to water containing male crab smell.

\section{CONCLUSION}

Mating behavior in the current study have depicts similar pattern of behavior with previous studies on other portunid crab such as Portunus sanguinolentus (Dinakaran and Soundarapandian, 2009) and also on P. pelagicus (Fielder and Eales, 1972). The results from this study is practicable in determining ways for accelerating molting in crabs so that mating process could be proceed. Besides, the results proved that limb autotomy technique can be used in crab aquaculture industries to speed up the production of soft-shell female crabs for a successful mating to occur therefore, fasten up the berried females crab production for a year round seed-stock supply.

\section{ACKNOWLEDGEMENTS}

The reseaerchers would like to thank E-science Fund under Agriculture Cluster, Ministry of Agriculture Malaysia for funding these project resources. Special thanks to Institute of Tropical Aquaculture, UMT for the facilities and equipments in the completion of this project.

\section{REFERENCES}

Anilkumar, G., K.G. Adiyodi and R.G. Adiyodi, 1981. Induced ovarian growth under bilateral and unilateral eyestalk ablation in the crab, Paratelphusa hydrodromous (Herbst). Proceedings of UK. Meeting, International Society of Invertebrate Reproduction. 
Baldwin, J. and S. Johnsen, 2008. The importance of color in mate choice of the blue crab Callinectes sapidus. J. Exp. Biol., 212: 3762-3768.

Brockerhoff, A.M. and C.L. McLay, 2005. Comparative analysis of the mating strategies in grapsid crabs with special reference to two common intertidal crabs, Cyclograpsus lavauxi and Helice crarsa from New Zealand. J. Crustacean Biol., 25: 507-520.

DeGoursey, R.E. and P.J. Auster, 1992. A mating aggregation of the spider crab (Libinia emarginata). J. Northwest Atl. Fish. Sci., 13: 77-82.

Dinakaran, G.K. and P. Soundarapandian, 2009. Mating behaviour and broodstock development of commercially important blue swimming crab, Portunus sanguinolentus (Herbst). Indian J. Sci. Technol., 2: 71-75.

Fielder, D.R. and A.J. Eales, 1972. Observations on courtship, mating and sexual maturity in Portunus pelagicus (L., 1766). J. Natural History, 6: 273-277.

Gleeson, R.A., 1980. Pheromone communication in the reproductive behavior of the blue crab Callinectes sapidus. Mar. Behav. Physiol., 7: 119-134.

Hartnoll, R.G., 1969. Mating in the brachyura. Crustaceana, 16: 161-181.

Holland, C.A. and D.M. Skinner, 1976. Interactions between molting and regeneration in Theland crab. Biol. Bull., 150: 222-240.

Hopkins, P.M., 1993. Regeneration of walking legs in the fiddler crab Uca pugilator. Amer. Zool., 33: 348-356.

Jaroensatasinee, M. and K. Jaroensatasinee, 2003. Male body size influence female choice and male male competition in the fiddler crab Uca paradussumieri Bott, 1973 (Decapoda, Brachyura, Ocypodidae). Crustaceana, 76: 177-186.

Jennings, A.C., C.L. McLay and A.M. Brockerhoff, 2000. Mating behavior of Macrophthalmus hirtipes. Marine Biology., 137: 267-278.

Juanes, F. and L.D. Smith, 1995. The ecological consequences of limb damage and loss in decapod crustaceans: A review and prospectus. J. Exp. Marine Biol. Ecol., 193: 197-223.

Kailola, P.J., M.J. Williamson, P.C. Stewart, R.E. Reichelt, A. McNee and C. Grieve, 1993. Australian Fisheries Resources. Bureau of Resource Sciences, Canberra, Australia.

Kamio, M., M.A. Reidenbach and C.D. Derby, 2008. To paddle or not: Context dependent courtship display by male blue crabs, Callinectes sapidus. J. Exp. Biol., 211: 1243-1248.

Kurup, K.N. and R.G. Adiyodi, 1984. Multiple limb autotomy can trigger either ovarian growth or somatic growth in the freshwater crab, Paratelphusa hydrodromous (Herbst). General Comparitive Endocrinol., 56: 433-443.
Lawrence, J.M., 1992. Arm Loss and Regeneration in Asteroidea (Echinodermata). In: Echinoderm Research 1991, Scalera-Liaci, L. and C. Canicatti (Eds.). A.A. Balkema, Rotterdam, pp: 39-52.

Lee, S.Y. and R. Seed, 1992. Ecological implications of cheliped size in crabs: Some data from Carcinus maenas and Liocarcinus holsatus. Mar. Ecol. Prog. Ser., 84: 150-160.

Maginnis, T.L., 2006. The costs of autotomy and regeneration in animals: A review and framework for future research. Int. Soc. Behavioral Ecol., 17: $857-872$.

Murata, A., M. Imafuku and N. Abe, 2006. Copulation by the barnacle Tetraclita japonica under natural conditions. J. Zool., 253: 275-280.

O'Brien, J.J. and D.M. Skinner, 1990. Overriding of the molt-inducing stimulus of multiple limb autotomy in the mud crab Rhithropanopeus harrisii by parasitization with a rhizocephalan. J. Crustacean Biol., 10: 440-445.

Patei, B. and D.J. Crisp, 1961. Relation between the breeding and molting cycles in cirripedes. Crustaceana, 2: 89-107.

Paterson, B., D. Mann, B. Kelly and M. Barchiesi, 2007. Limb-loss in pond-reared blue swimmer crabs Portunus pelagicus (L.): effect on growth in an indoor shedding system. Aquacult. Res., 38: 1569-1579.

Reaka, M.L., 1976. Lunar and tidal periodicity of molting and reproduction in stomatopod crustacea: A selfish herd hypothesis. Biol. Bull. Woods Hole Mass., 150: 468-490.

Rufino, M.M. and D.A. Jones, 2001. Observations on the function of the fifth pereiopod in late stage larvae of Lysmata debelius (Decapoda, Hippolytidae). Crustaceana, 74: 977-990.

Ryan, E.P., 1976. Pheromone: Evidence in decapod. Crustacean Sci., 151: 340-341.

Seidel, R., 2005. Rapid hydrostatic limb inflation in the prawn Macrobrachium lar. J. Crustacean Biol., 25: $460-461$.

Simonson, J.L. and P. Steele, 1981. Cheliped asymmetry in the stone crab, Menippe mercenaria, with notes on claw reversal and regeneration. North. Gulf Sci., 5: 21-30.

Skinner, D.M. and D.E. Graham, 1972. Loss of limbs as a stimulus to ecdysis in Brachyura (true crabs). Biol. Bull. Woods Hole, Mass., 143: 222-233.

Skinner, D.M., 1985. Molting and Regeneration. In: The Biology of Crustacea, Bliss, D.E. and L.H. Mantel (Eds.). Vol. 9, Academic Press, New York, pp: 43-146. 
Smith, L.D., 1990. Patterns of limb loss in the blue crab Callinectes sapidus and the effects of autotomy on growth. Bull. Mar. Sri., 46: $23-36$.

Subramoniam, T., 2000. Crustacean ecdysteriods in reproduction and embryogenesis. Comp. Biochem. Physiol. Part C, 125: 135-156.
Taylor, J.R.A. and W.M. Kier, 2003. Switching skeletons: Hydrostatic support in molting crabs. Science, 301: 209-210.

Teytaud, A.R., 1971. The laboratory studies of sex recognition in the blue crab Callinectes sapidus Rathbun. Sea Grant Technical Bulletin No. 15. University of Miami Sea Grant Prog., pp: 62. 